\title{
Determinants of ${ }^{18} \mathrm{~F}$-NaF uptake in femoral arteries in patients with type 2 diabetes mellitus
}

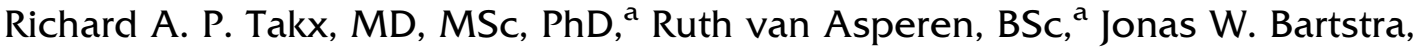 \\ MSc, ${ }^{\text {a }}$ Sabine R. Zwakenberg, PhD, ${ }^{\text {b }}$ Jelmer M. Wolterink, PhD, ${ }^{c}$ Csilla Celeng, \\ $\mathrm{MD}, \mathrm{PhD},{ }^{\mathrm{a}}$ Pim A. de Jong, MD, PhD, and Joline W. Beulens, $\mathrm{PhD}^{\mathrm{d}}$ \\ a Department of Radiology, University Medical Center Utrecht, Utrecht, The Netherlands \\ b Julius Center for Health Sciences and Primary Care, University Medical Center Utrecht, Utrecht, \\ The Netherlands \\ c Image Sciences Institute, University Medical Center Utrecht, Utrecht, The Netherlands \\ d Department of Epidemiology \& Biostatistics, Amsterdam Public Health Research Institute, Vrije \\ Universiteit, University Medical Center, Amsterdam, The Netherlands
}

Received Dec 20, 2019; accepted Feb 27, 2020

doi: $10.1007 /$ s12350-020-02099-z

Background. The goal of this study was to investigate the potential determinants of ${ }^{18} \mathrm{~F}-\mathrm{NaF}$ uptake in femoral arteries as a marker of arterial calcification in patients with type 2 diabetes and a history of arterial disease.

Methods and Results. The study consisted of participants of a randomized controlled trial to investigate the effect of vitamin K2 (NCT02839044). In this prespecified analysis, subjects with type 2 diabetes and known arterial disease underwent full body ${ }^{18}$ F-NaF PET/CT. Targetto-background ratio (TBR) was calculated by dividing the mean $S U V_{\text {max }}$ from both superficial femoral arteries by the $\mathrm{SUV}_{\text {mean }}$ in the superior vena cava (SVC) and calcium mass was measured on CT. The association between ${ }^{18} \mathrm{~F}-\mathrm{NaF}$ TBR and cardiovascular risk factors was investigated using uni- and multivariate linear regression corrected for age and sex. In total, 68 patients (mean age: $69 \pm 8$ years; male: 52) underwent ${ }^{18} \mathrm{~F}$-NaF PET/CT. Higher CT calcium mass, total cholesterol, and HbA1c were associated with higher ${ }^{18} \mathrm{~F}$-NaF TBR after adjusting.

Conclusion. This study shows that several modifiable cardiovascular risk factors (total cholesterol, triglycerides, HbA1c) are associated with femoral ${ }^{18} \mathrm{~F}$-NaF tracer uptake in patients with type 2 diabetes. (J Nucl Cardiol 2021;28:2700-5.)

Key Words: PAD $\cdot$ diabetes $\cdot$ atherosclerosis $\cdot$ PET $\cdot$ CT

\begin{tabular}{|llll|}
\hline Abbreviations & SVC & Superior vena cava \\
${ }^{18}$ F-NaF & Sodium 18F-fluoride & TBR & Target-to-background ratio \\
ABI & Ankle brachial index & & \\
MAC & Medial arterial calcification & & \\
SUV & Standardized uptake value & \\
\hline
\end{tabular}

\section{See related editorial, pp. 2706-2711}

Electronic supplementary material The online version of this article (https://doi.org/10.1007/s12350-020-02099-z) contains supplementary material, which is available to authorized users.

Funding This study was funded by Dr. Dekker grant (2013T120) from the Dutch Heart Foundation.

The authors of this article have provided a PowerPoint file, available for download at SpringerLink, which summarizes the contents of the paper and is free for re-use at meetings and presentations. Search for the article DOI on SpringerLink.com.
The authors have also provided an audio summary of the article, which is available to download as ESM, or to listen to via the JNC/ASNC Podcast.

All editorial decisions for this article, including selection of reviewers and the final decision, were made by guest editor Robert deKemp, $\mathrm{PhD}$.

Reprint requests: Richard A. P. Takx, MD, MSc, PhD, Department of Radiology, University Medical Center Utrecht, Heidelberglaan 100, 3584 CX Utrecht, The Netherlands; r.a.p.takx@umcutrecht.nl $1071-3581 / \$ 34.00$

Copyright (C) 2020 The Author(s) 


\section{INTRODUCTION}

Arterial calcification on CT is used as a marker for the presence of intimal calcification (atherosclerosis) and medial arterial calcification. Microcalcifications $(<50 \mu \mathrm{m})$ are observed in the early stages of the calcification process and are possibly associated with plaque rupture, whereas macrocalcifications contribute to stability of atherosclerotic plaques. ${ }^{1}$ In addition, microcalcifications in the internal elastic lamina and in the tunica media, ${ }^{2,3}$ may be related to arterial stiffening. ${ }^{4}$ CT allows to identify macrocalcifications of over $200 \mu \mathrm{m}$ in diameter. ${ }^{5}$ Sodium $18 \mathrm{~F}$-fluoride $\left({ }^{18} \mathrm{~F}-\mathrm{NaF}\right)$ $\mathrm{PET} / \mathrm{CT}$ is a novel imaging technique that can visualize smaller calcifications. ${ }^{6-10}$ In the femoral arteries, ${ }^{18} \mathrm{~F}$ $\mathrm{NaF}$ PET can visualize ongoing (medial and intimal) calcification. ${ }^{11}$ In the coronaries ${ }^{18} \mathrm{~F}-\mathrm{NaF}$ PET is associated with high risk plaque features and plaque rupture. $^{6}$ In patients with diabetes, additional to atherosclerosis, medial arterial calcification (MAC or Mönckeberg's sclerosis) is highly prevalent and is associated with increased arterial stiffness, hypertension, distal symmetrical neuropathy, chronic kidney disease, cardiovascular and all-cause mortality. ${ }^{12-14}$ MAC is observed in arteries of the lower extremity across the entire length. ${ }^{3} \mathrm{~A}$ recent study showed that increased ${ }^{18} \mathrm{~F}$ $\mathrm{NaF}$ PET accumulation in the femoral arteries is associated with diffuse calcium deposition and significantly correlates with cardiovascular risk factors. ${ }^{11}$ Several studies investigated determinants of ${ }^{18} \mathrm{~F}-\mathrm{NaF}$ uptake in oncologic patients. ${ }^{11,15}$ While the use of ${ }^{18} \mathrm{~F}$ $\mathrm{NaF}$ is increasing, the available data are limited regarding its uptake values and potential uptake modifiers in high CVD risk groups such as diabetes patients. The goal of this study is to investigate the potential determinants of ${ }^{18} \mathrm{~F}-\mathrm{NaF}$ uptake as a marker of arterial calcification in patients with type 2 diabetes and a history of arterial disease.

\section{METHOD}

\section{Study Design and Population}

The study population consisted of participants of a randomized controlled trial (ClinicalTrials.gov Identifier: NCT02839044). ${ }^{16,17}$ Patients were recruited at the University Medical Center Utrecht between June 2016 and September 2018. The goal of the study was to investigate the effect of vitamin $\mathrm{K} 2$ supplementation on arterial calcification in patients with type 2 diabetes. Inclusion criteria were age $>40$ years with type 2 diabetes and documented presence of cardiovascular disease. The presence of arterial diseases was defined as coronary artery disease, stroke, peripheral artery disease, abdominal aortic aneurysm or an ankle brachial index (ABI) of $<0.9$. The study protocol was approved by the local medical ethical committee (NL53572.041.15, METC 15/571) and all patients provided written informed consent. In this prespecified analysis, baseline ${ }^{18} \mathrm{~F}-\mathrm{NaF}$ PET/CT scans and patient data were used to determine the potential contributors of increased ${ }^{18} \mathrm{~F}-\mathrm{NaF}$ uptake. Patient data were collected from questionnaires and available medical records. All participants completed a questionnaire on medical history, medication, smoking history, and a physical examination including height, weight and blood pressure. Non-fasting blood samples were collected to measure cholesterol levels, HbAlc levels and creatinine.

\section{PET/CT Imaging and Quantification}

All patients underwent a full body ${ }^{18} \mathrm{~F}-\mathrm{NaF}$ PET/CT scan, performed on a Siemens Biograph 40 scanner (Siemens Healthineers, Erlangen, Germany). Imaging was performed $90 \mathrm{~min}$ after intravenous injection of $2.0 \mathrm{MBq} / \mathrm{kg}{ }^{18} \mathrm{~F}-\mathrm{NaF}$, with a maximum dosage of $200 \mathrm{MBq}$. Circular regions of interest (ROI) were drawn bilaterally around the superficial femoral arteries (see Figure 1A and B) from the bifurcation of the femoral artery to the femur condyles on every sequential axial slice to determine the ${ }^{18} \mathrm{~F}-\mathrm{NaF}$ uptake. To derive the average maximum standardized uptake value $\left(\mathrm{SUV}_{\max }\right)$, maximum values measured per ROI were summed and averaged. Target-to-background ratio (TBR) was calculated by dividing the mean $\mathrm{SUV}_{\text {max }}$ from both femoral arteries by the $\mathrm{SUV}_{\text {mean }}$ from three sequential slices in the SVC (see Figure 1C), the circular ROI size was not fixed as the vena cava size differs between individuals. The femoral artery TBR was used as the measure of femoral ${ }^{18} \mathrm{~F}-\mathrm{NaF}$ PET activity. To evaluate interrater reproducibility on radiotracer uptake ten participants were randomly selected and analyzed by thee blinded raters.

\section{Calcification Quantification}

Non-contrast-enhanced CT scans were visually evaluated using in-house built software to identify calcium scores in the femoral arteries. A threshold of $\geq 130$ Hounsfield units was used and calcification was quantified using the calcium mass equivalent score which considers calcification volume and density.

\section{Statistical Analyses}

Normality of the data was tested using Quantile-Quantile plots. Descriptive data were expressed as mean \pm standard deviation (SD) for normally distributed continuous variables, and median (Q1-Q3) for non-normally distributed continuous variables. Categorical variables are displayed as count (percentage). Reliability for TBR measurements was assessed using intraclass correlation coefficient. Univariate linear regression (unstandardized betas) was used to identify associations between all variables and ${ }^{18} \mathrm{~F}-\mathrm{NaF}$ TBR. Multivariate linear analysis was performed to correct for age and sex. No adjustments were made for multiplicity of testing, and no imputation was used for missing values (only 3 patients had missing data on calcium mass). A $p$ value $<0.05$ was 


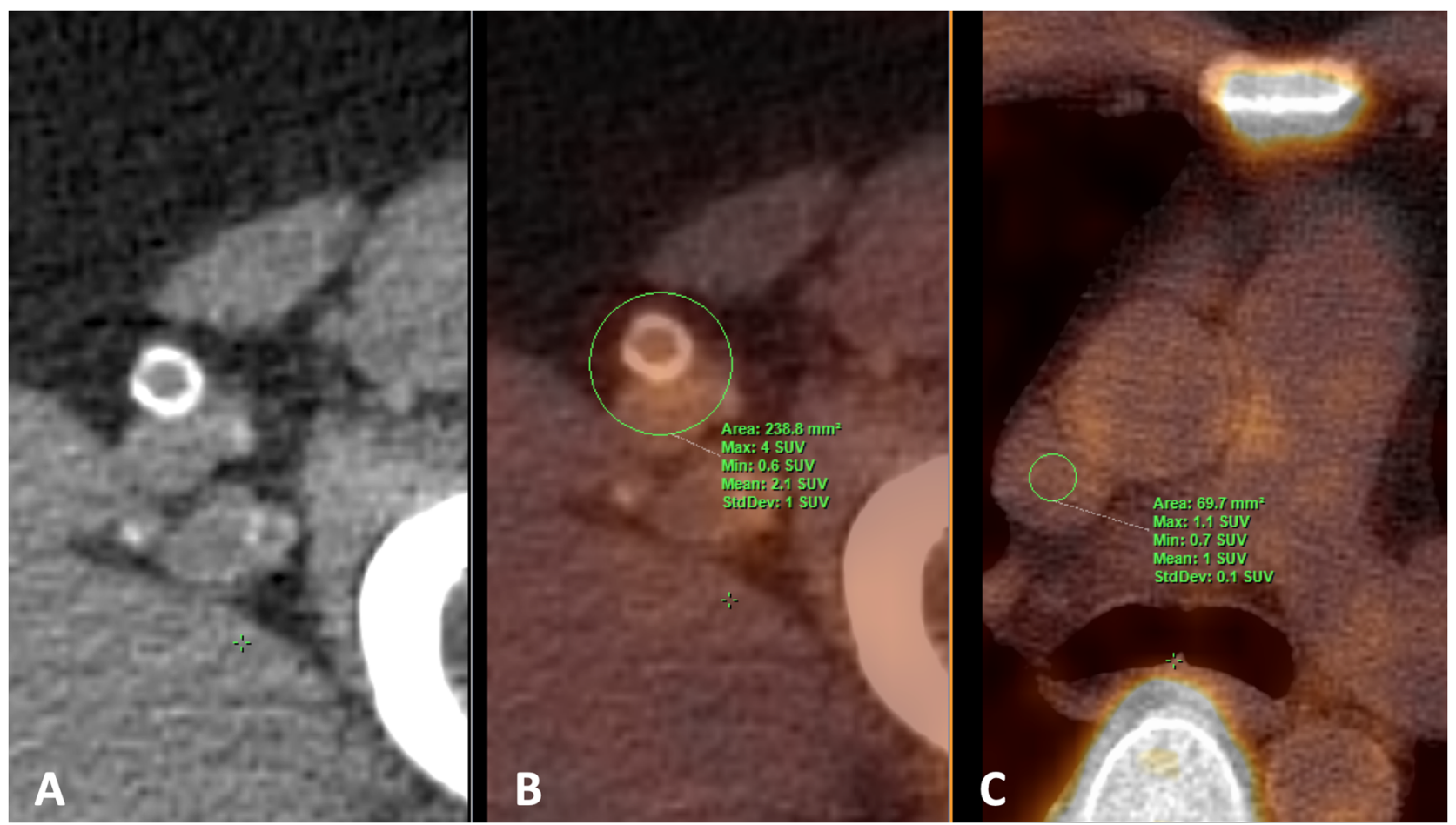

Figure 1. Axial CT image A showing circular calcification in the superficial femoral artery and fusion image $\mathbf{B}$ with a circular region of interest (ROI) drawn for quantification ${ }^{18} \mathrm{~F}-\mathrm{NaF}$ SUVmax in the femoral artery. Axial fusion image $(\mathbf{C})$ demonstrating background measurement of ${ }^{18} \mathrm{~F}-\mathrm{NaF}$ SUVmean in the superior vena cava using a circular ROI.

considered statistically significant. Statistical analyses were performed using SPSS software (IBM Corp, Version 24.0. Armonk, NY, USA).

\section{RESULTS}

\section{Patient Characteristics}

The study population consisted of 68 participants (76\% male) with a mean age $69 \pm 8$ years. Glucose lowering drugs were used by $60(88 \%)$ patients, while insulin was used in 32 patients $(47 \%)$. In total 25 patients used both insulin and glucose lowering drugs and only one patient was neither on insulin nor glucose lowering drugs. Fifty-two participants (77\%) were treated with statins. As defined by the inclusion criteria all patients had a history of cardiovascular disease. Femoral arterial calcification on CT was present in 97\% of the study population. Arterial ${ }^{18} \mathrm{~F}-\mathrm{NaF}$ was measured on average on 76 slices per patient (38 per side). Baseline characteristics of the patients are reported in Table 1.

\section{${ }^{18}$ F-NaF PET Activity}

Higher femoral calcium mass on CT, total cholesterol, and $\mathrm{HbAlc}$ were associated with higher ${ }^{18} \mathrm{~F}-\mathrm{NaF}$ TBR (Table 2). Age, blood pressure, creatine and body mass index (BMI) were not associated to ${ }^{18} \mathrm{~F}-\mathrm{NaF}$ TBR. When applying multivariate linear regression adjusting for age and sex, CT femoral calcium mass, total cholesterol and $\mathrm{HbA} 1 \mathrm{c}$ remained significantly associated (Table 2). A trend towards significance was seen for higher triglycerides and higher ${ }^{18} \mathrm{~F}-\mathrm{NaF}$ PET TBR $(\mathrm{p}=0.052) .{ }^{18} \mathrm{~F}-\mathrm{NaF}$ PET TBR was lower in patients on statins with a trend towards significance $(\mathrm{p}=0.058)$. No significant differences in TBR were observed for smokers, male sex or other medication (Table 2). The intraclass correlation coefficient for inter-rater reliability of radiotracer uptake (measured as TBR) was excellent with a value of 0.98 (95\% CI 0.94-0.99).

\section{DISCUSSION}

This study provides several observations that contribute to our understanding of the determinants of ${ }^{18} \mathrm{~F}$ $\mathrm{NaF}$ PET in the femoral arteries of patients with type 2 diabetes and a history of arterial disease. Firstly, we 
Table 1. Patient characteristics of the study population

\begin{tabular}{|c|c|}
\hline Clinical characteristics & $N=68$ \\
\hline Age (years) & $69 \pm 8$ \\
\hline Male & $52(76)$ \\
\hline \multicolumn{2}{|l|}{ Blood pressure } \\
\hline Systolic (mmHg) & $137 \pm 18$ \\
\hline Diastolic (mmHg) & $72 \pm 11$ \\
\hline Body mass index $\left(\mathrm{kg} / \mathrm{m}^{2}\right)$ & $31.2 \pm 5.3$ \\
\hline \multicolumn{2}{|l|}{ Smokers } \\
\hline Former & $42(62)$ \\
\hline Current & $10(15)$ \\
\hline Femoral 18F-NaF PET TBR & $2.2 \pm 0.7$ \\
\hline Femoral calcium mass by $\mathrm{CT}$ & $118(14-451)$ \\
\hline \multicolumn{2}{|l|}{ Cholesterol } \\
\hline Total $(\mathrm{mmol} / \mathrm{l})$ & $4.4[3.5-5]$ \\
\hline LDL (mmol/l) & $2.1[1.4-2.5]$ \\
\hline $\mathrm{HDL}(\mathrm{mmol} / \mathrm{l})$ & $1.1 \pm 0.3$ \\
\hline Triglycerides (mmol/l) & $2.9[1.6-3.4]$ \\
\hline $\mathrm{HbA} 1 \mathrm{c}(\mathrm{mmol} / \mathrm{mol})$ & $58.2[47.3-63.0]$ \\
\hline Serum creatine $(\mu \mathrm{mol} / \mathrm{l})$ & $85.2 \pm 23.4$ \\
\hline \multicolumn{2}{|l|}{ History of arterial disease } \\
\hline CAD & $41(60)$ \\
\hline CVA, TIA & $23(34)$ \\
\hline PAD & $16(24)$ \\
\hline $\mathrm{ABI}<0.9$ & $18(27)$ \\
\hline AAA & $6(9)$ \\
\hline \multicolumn{2}{|l|}{ Medication use } \\
\hline Insulin & $32(47)$ \\
\hline Glucose lowering drugs & $60(88)$ \\
\hline Statins & $52(77)$ \\
\hline Lipid lowering drugs & $31(46)$ \\
\hline Bisphosphonates & $1(2)$ \\
\hline Antihypertensive drugs & $60(88)$ \\
\hline Platelet inhibitors & $31(46)$ \\
\hline Calcium supplements & $9(13)$ \\
\hline Vitamin D supplements & $21(31)$ \\
\hline
\end{tabular}

Values are represented as mean $\pm S D$, median $[Q 1-Q 3]$ or $n$ (\%)

$T B R$, target-to-background ratio; $L D L$, low-density lipoprotein; $H D L$, high-density lipoprotein; $H b A 1 c$, glycated hemoglobin; $C A D$, coronary artery disease; CVA, TIA, cerebrovascular disease, transient ischemic attack; $P A D$, peripheral artery disease; $A B I<0.9$, ankle brachial index $<0.9 ; A A A$, abdominal aortic aneurysm

showed that femoral calcium mass on $\mathrm{CT}$ is positively associated with ${ }^{18} \mathrm{~F}-\mathrm{NaF}$ uptake. Second, several cardiovascular risk factors including total cholesterol, triglycerides and $\mathrm{HbAlc}$ were associated with ${ }^{18} \mathrm{~F}-\mathrm{NaF}$ uptake in patients with type 2 diabetes. Together, these data suggest that ${ }^{18} \mathrm{~F}-\mathrm{NaF}$ uptake is an important imaging biomarker of arterial disease burden both related to dyslipidemia and diabetes control even in extensively treated patients.

Previous research showed that multiple cardiovascular risk factors are associated with ${ }^{18} \mathrm{~F}-\mathrm{NaF}$ uptake. Derlin et a ${ }^{15}$ examined ${ }^{18} \mathrm{~F}-\mathrm{NaF}$ in the carotid arteries in 269 oncologic patients. ${ }^{18} \mathrm{~F}-\mathrm{NaF}$ uptake was significantly associated with age, male sex, hypertension and hypercholesterolemia. In a different study among 409 oncologic patients, the association between ${ }^{18} \mathrm{~F}-\mathrm{NaF}$ accumulation in femoral arteries with cardiovascular risk factors and calcified plaque burden was demonstrated. ${ }^{11}$ In both studies, hypercholesterolemia was associated with increased ${ }^{18} \mathrm{~F}-\mathrm{NaF}$ uptake, which is in line with our study. An association between $\mathrm{HbAlc}$ and ${ }^{18} \mathrm{~F}-\mathrm{NaF}$ uptake, had been observed in healthy controls. ${ }^{18}$ In patients with diabetes, high HbAlc is known to be associated with osteocalcin, which supports the concept of vascular calcification in patients with diabetes. ${ }^{19}$ Blomberg et al ${ }^{18}$ investigated ${ }^{18} \mathrm{~F}-\mathrm{NaF}$ uptake in the coronary arteries of 89 healthy adults. According to their results age, female sex and BMI were independent determinants of increased coronary ${ }^{18} \mathrm{~F}-\mathrm{NaF}$ uptake. In our study we did not find an association between age, sex or BMI and ${ }^{18} \mathrm{~F}-\mathrm{NaF}$ uptake. The differences in associations between cardiovascular determinants and ${ }^{18} \mathrm{~F}-\mathrm{NaF}$ uptake compared to our study could be explained by the differences in study population (our cohort consisted predominantly out of males with a high $\mathrm{BMI}$ ), investigated vessels beds ${ }^{20}$ and inclusion criteria.

${ }^{18} \mathrm{~F}-\mathrm{NaF}$ uptake is significantly higher in microcalcifications compared to macrocalcifications. ${ }^{21}$ Irkle et $\mathrm{al}^{21}$ demonstrated using preclinical $\mu \mathrm{PET} / \mu \mathrm{CT}$ that microcalcifications have no barriers for penetration, while ${ }^{18} \mathrm{~F}-\mathrm{NaF}$ cannot penetrate into the deeper layers of macrocalcifications. Also, microcalcifications have a relatively big surface area compared to their volume. In a prior longitudinal study, we observed that areas without calcification on $\mathrm{CT}$, but with increased ${ }^{18} \mathrm{~F}$ $\mathrm{NaF}$ uptake, had more arterial calcification at followup. ${ }^{17}$ These could represent microcalcifications not yet detectable on CT. ${ }^{17}$ In the current study CT detected arterial calcification was related to ${ }^{18} \mathrm{~F}-\mathrm{NaF}$ uptake, suggesting a significant effect of large calcium depositions on tracer uptake with clinical PET/CT systems.

An important strength of the current study is that images were acquired $90 \mathrm{~min}$ after tracer injection. The 90 min time-point is considered to be advantageous, because of the balance between signal-to-background ratio and patient comfort. For comparability with other studies we used TBR as our measure of ${ }^{18} \mathrm{~F}-\mathrm{NaF}$ uptake for research. ${ }^{15}$ There is debate on how to quantify arterial calcification with $\mathrm{NaF}$ PET. ${ }^{22-24}$ We calculated 
Table 2. Uni- and multivariate linear regression of TBR

\begin{tabular}{|c|c|c|c|c|}
\hline Clinical characteristics & Univariate $\beta(95 \% \mathrm{CI})$ & p value & Multivariate $\beta(95 \% \mathrm{CI})$ & p value \\
\hline Age (years) & $0.05(-0.015$ to 0.025$)$ & 0.614 & NA & \\
\hline Female sex & $-0.025(-0.428$ to 0.349$)$ & 0.838 & NA & \\
\hline \multicolumn{5}{|l|}{ Blood pressure } \\
\hline Systolic (mmHg) & $-0.002(-0.012$ to 0.007$)$ & 0.644 & $-0.003(-0.013$ to 0.007$)$ & 0.516 \\
\hline Diastolic (mmHg) & $-0.010(-0.026$ to 0.005$)$ & 0.189 & $-0.010(-0.027$ to 0.007$)$ & 0.229 \\
\hline Body mass index $\left(\mathrm{kg} / \mathrm{m}^{2}\right)$ & $0.019(-0.012$ to 0.050$)$ & 0.222 & $0.026(-0.008$ to 0.060$)$ & 0.127 \\
\hline Femoral calcium mass by $\mathrm{CT}^{*}$ & $0.349(0.204-0.494)$ & $<0.001$ & $0.417(0.251-0.582)$ & $<0.001$ \\
\hline \multicolumn{5}{|l|}{ Cholesterol } \\
\hline Total (mmol/l) & $0.159(0.034-0.284)$ & 0.013 & $0.168(0.040-0.296)$ & 0.011 \\
\hline $\mathrm{LDL}(\mathrm{mmol} / \mathrm{l})$ & $0.111(-0.071$ to 0.292$)$ & 0.227 & $0.120(-0.069$ to 0.308$)$ & 0.210 \\
\hline $\mathrm{HDL}(\mathrm{mmol} / \mathrm{l})$ & $-0.012(-0.626$ to 0.602$)$ & 0.969 & $-0.045(-0.706$ to 0.616$)$ & 0.891 \\
\hline Triglycerides (mmol/l) & $0.044(-0.003$ to 0.090$)$ & 0.064 & $0.048(0.000-0.095)$ & 0.052 \\
\hline $\mathrm{HbA} 1 \mathrm{c}(\mathrm{mmol} / \mathrm{mol})$ & $0.011(0.000-0.021)$ & 0.042 & $0.014(0.003-0.025)$ & 0.015 \\
\hline Serum creatinine $(\mu \mathrm{mol} / \mathrm{l})$ & 0.001 ( -0.006 to 0.008$)$ & 0.847 & $0.000(-0.008$ to 0.008$)$ & 0.965 \\
\hline Current smokers & $-0.042(-0.507$ to 0.424$)$ & 0.858 & $-0.030(-0.504$ to 0.444$)$ & 0.900 \\
\hline \multicolumn{5}{|l|}{ Medication use } \\
\hline Insulin & $0.245(-0.080$ to 0.570$)$ & 0.137 & $0.283(-0.056$ to 0.622$)$ & 0.100 \\
\hline Statins & $-0.349(-0.728$ to 0.030$)$ & 0.070 & $-0.237(-0.762$ to 0.014$)$ & 0.058 \\
\hline Glucose lowering drugs & $-0.199(-0.708$ to 0.311$)$ & 0.439 & $-0.268(-0.812$ to 0.276$)$ & 0.329 \\
\hline Lipid lowering drugs & $0.009(-0.322$ to 0.340$)$ & 0.957 & $0.014(-0.323$ to 0.350$)$ & 0.934 \\
\hline Antihypertensive & $-0.146(-0.656$ to 0.365$)$ & 0.571 & $-0.136(-0.656$ to 0.385$)$ & 0.605 \\
\hline Platelet inhibitors & $0.155(-0.251$ to 0.561$)$ & 0.448 & $0.147(-0.277$ to 0.571$)$ & 0.490 \\
\hline Calcium supplements & $0.383(-0.094$ to 0.860$)$ & 0.114 & $0.399(-0.097$ to 0.895$)$ & 0.113 \\
\hline Vitamin D supplements & $0.242(-0.110$ to 0.594$)$ & 0.175 & $0.234(-0.130$ to 0.597$)$ & 0.203 \\
\hline
\end{tabular}

Multivariate linear regression age and sex adjusted. $\beta$ is per one unit change

${ }^{*} \log$ (coronary calcium score plus 1 )

the TBR using the average of the SUVmax of each femoral artery slice. Though SUVmax is sensitive to noise, it can also be a good measure of the maximum disease burden in a slice. ${ }^{22,23}$ By averaging (76 slices per patient) the noise effect is reduced to some extent. Others advocate the SUVmean for an individual slice, ${ }^{24}$ which is less limited by noise, but also averages nondiseased parts of the artery and the blood pool. Differences in PET SUV quantification will influence the observed result therefore it would be important to achieve uniform quantification methods. Other limitations are the relative small sample size and the lack of prospective outcome data.

In conclusion, we showed that cardiovascular risk factors including total cholesterol, triglycerides and $\mathrm{HbA1c}$ are associated with ${ }^{18} \mathrm{~F}-\mathrm{NaF}$ uptake and calcification in the femoral arteries in patients with type 2 diabetes mellitus and a history of arterial disease. Our findings show that ${ }^{18} \mathrm{~F}-\mathrm{NaF}$ uptake can be an imaging biomarker of arterial disease burden both related to dyslipidemia and diabetes control. Larger studies are needed to investigate whether these findings are generalizable to non-diabetic patients with cardiovascular diseases and if (further) modification of these risk factors is beneficial for ${ }^{18} \mathrm{~F}-\mathrm{NaF}$ uptake and outcome.

\section{NEW KNOWLEDGE GAINED}

${ }^{18} \mathrm{~F}-\mathrm{NaF}$ uptake may be an important arterial imaging biomarker related to dyslipidemia and diabetes control (HbA1c) even in extensively treated patients with type 2 diabetes.

\section{Disclosure}

$R A P T, R v A, J W B, J M W, C C$ and PAdJ report no financial support or conflict of interest. SRZ and JWB are supported by the Senior Dr. Dekker grant (2013T120) from the Dutch Heart Foundation.

\section{Ethical Approval}

All procedures performed in studies involving human participants were in accordance with the ethical standards of the institutional and national research committee and with the 
1964 Helsinki declaration and its later amendments or comparable ethical standards. Informed consent was obtained from all individual participants included in the study.

\section{Open Access}

This article is licensed under a Creative Commons Attribution 4.0 International License, which permits use, sharing, adaptation, distribution and reproduction in any medium or format, as long as you give appropriate credit to the original author(s) and the source, provide a link to the Creative Commons licence, and indicate if changes were made. The images or other third party material in this article are included in the article's Creative Commons licence, unless indicated otherwise in a credit line to the material. If material is not included in the article's Creative Commons licence and your intended use is not permitted by statutory regulation or exceeds the permitted use, you will need to obtain permission directly from the copyright holder. To view a copy of this licence, visit http://creativecommons.org/licenses/by/4.0/.

\section{References}

1. Shioi A, Ikari Y. Plaque calcification during atherosclerosis progression and regression. J Atheroscler Thromb 2018;25:294-303.

2. Narula N, Dannenberg AJ, Olin JW, Bhatt DL, Johnson KW, Nadkarni G, et al. Pathology of peripheral artery disease in patients with critical limb ischemia. J Am Coll Cardiol 2018;72:2152-63.

3. Torii S, Mustapha JA, Narula J, Mori H, Saab F, Jinnouchi H, et al. Histopathologic characterization of peripheral arteries in subjects with abundant risk factors: correlating imaging with pathology. JACC Cardiovasc Imaging 2019;12:1501-13.

4. Kamenskiy A, Poulson W, Sim S, Reilly A, Luo J, MacTaggart J. Prevalence of calcification in human femoropopliteal arteries and its association with demographics, risk factors, and arterial stiffness. Arterioscler Thromb Vasc Biol 2018;38:e48-57.

5. Sarwar A, Rieber J, Mooyaart EA, Seneviratne SK, Houser SL, Bamberg F, et al. Calcified plaque: measurement of area at thinsection flat-panel CT and 64-section multidetector CT and comparison with histopathologic findings. Radiology 2008;249:301-6.

6. Joshi NV, Vesey AT, Williams MC, Shah AS, Calvert PA, Craighead $\mathrm{FH}$, et al. 18F-fluoride positron emission tomography for identification of ruptured and high-risk coronary atherosclerotic plaques: A prospective clinical trial. Lancet 2014;383:70513

7. (7) Al-Zaghal A, Mehdizadeh Seraj S, Werner TJ, Gerke O, Hoilund-Carlsen PF, Alavi A. Assessment of physiological intracranial calcification in healthy adults using (18)F-NaF PET/ CT. J Nucl Med 2018.

8. Krishnan S, Otaki Y, Doris M, Slipczuk L, Arnson Y, Rubeaux M, et al. Molecular imaging of vulnerable coronary plaque: A pathophysiologic perspective. J Nucl Med 2017;58:359-64.

9. Hop H, de Boer SA, Reijrink M, Kamphuisen PW, de Borst MH, Pol RA, et al. (18)F-sodium fluoride positron emission tomography assessed microcalcifications in culprit and non-culprit human carotid plaques. J Nucl Cardiol 2019;26:1064-75.

10. Bellinge JW, Francis RJ, Majeed K, Watts GF, Schultz CJ. In search of the vulnerable patient or the vulnerable plaque: (18)F- sodium fluoride positron emission tomography for cardiovascular risk stratification. J Nucl Cardiol 2018;25:1774-83.

11. Janssen T, Bannas P, Herrmann J, Veldhoen S, Busch JD, Treszl A, et al. Association of linear (1)(8)F-sodium fluoride accumulation in femoral arteries as a measure of diffuse calcification with cardiovascular risk factors: A PET/CT study. J Nucl Cardiol 2013;20:569-77.

12. Ho CY, Shanahan CM. Medial arterial calcification: An overlooked player in peripheral arterial disease. Arterioscler Thromb Vasc Biol 2016;36:1475-82.

13. Lanzer P, Boehm M, Sorribas V, Thiriet M, Janzen J, Zeller T, et al. Medial vascular calcification revisited: Review and perspectives. Eur Heart J 2014;35:1515-25.

14. Jeffcoate WJ, Rasmussen LM, Hofbauer LC, Game FL. Medial arterial calcification in diabetes and its relationship to neuropathy. Diabetologia 2009;52:2478-88

15. Derlin T, Wisotzki C, Richter U, Apostolova I, Bannas P, Weber $\mathrm{C}$, et al. In vivo imaging of mineral deposition in carotid plaque using 18F-sodium fluoride PET/CT: Correlation with atherogenic risk factors. J Nucl Med 2011;52:362-8

16. Zwakenberg SR, de Jong PA, Bartstra JW, van Asperen R, Westerink $\mathrm{J}$, de Valk $\mathrm{H}$, et al. The effect of menaquinone-7 supplementation on vascular calcification in patients with diabetes: A randomized, double-blind, placebo-controlled trial. Am J Clin Nutr 2019;110:883-90.

17. (17) den Harder AM, Wolterink JM, Bartstra JW, Spiering W, Zwakenberg SR, Beulens JW et al. Vascular uptake on (18)Fsodium fluoride positron emission tomography: precursor of vascular calcification? J Nucl Cardiol 2020.

18. Blomberg BA, Thomassen A, de Jong PA, Lam MGE, Diederichsen ACP, Olsen MH, et al. Coronary fluorine-18-sodium fluoride uptake is increased in healthy adults with an unfavorable cardiovascular risk profile: Results from the CAMONA study. Nucl Med Commun 2017;38:1007-14.

19. Flammer AJ, Gossl M, Li J, Matsuo Y, Reriani M, Loeffler D, et al. Patients with an $\mathrm{HbAlc}$ in the prediabetic and diabetic range have higher numbers of circulating cells with osteogenic and endothelial progenitor cell markers. J Clin Endocrinol Metab 2012;97:4761-8.

20. O'Neill WC, Han KH, Schneider TM, Hennigar RA. Prevalence of nonatheromatous lesions in peripheral arterial disease. Arterioscler Thromb Vasc Biol 2015;35:439-47.

21. Irkle A, Vesey AT, Lewis DY, Skepper JN, Bird JL, Dweck MR, et al. Identifying active vascular microcalcification by (18)Fsodium fluoride positron emission tomography. Nat Commun 2015;6:7495.

22. Blomberg BA, Thomassen A, de Jong PA, Simonsen JA, Lam MG, Nielsen AL, et al. Impact of personal characteristics and technical factors on quantification of sodium $18 \mathrm{~F}$-fluoride uptake in human arteries: Prospective evaluation of healthy subjects. J Nucl Med 2015;56:1534-40.

23. Blomberg BA, Thomassen A, Takx RA, Vilstrup MH, Hess S, Nielsen AL, et al. Delayed sodium 18F-fluoride PET/CT imaging does not improve quantification of vascular calcification metabolism: Results from the CAMONA study. J Nucl Cardiol 2014;21:293-304

24. (24) Sorci O, Batzdorf AS, Mayer M, Rhodes S, Peng M, Jankelovits AR et al. (18)F-sodium fluoride PET/CT provides prognostic clarity compared to calcium and Framingham risk scoring when addressing whole-heart arterial calcification. Eur J Nucl Med Mol Imaging 2019.

Publisher's Note Springer Nature remains neutral with regard to jurisdictional claims in published maps and institutional affiliations. 